from any college or university, whether Irish, Scotch, or Continental.

I want to know by whom the prosecution in the unfortunate Dr. Lobo's case was brought, whether by the Apothecaries' Company, or by the rich and powerful! "Medical Protection Society," (who have, or are said to have mustered some 800 out of the 30,000 members of the profession,) or by some private individual. I consider it a very illiberal proceeding, to select a poor foreign medical man for prosecution, when, taking the most favourable view you can, there are, at the least, some twenty practising (many of them visiting) druggists to one illegal medical practitioner, at the present time, and if the profession want to do any good, let them stop at once the druggist from prescribing, by a prosecution, and then the profession will be really and substantially benefited; for the druggists, and druggists alone, spoil half the practice of both London and provincial medical men. There are numbers of surgeons with only the college diploma, compounding all their own prescriptions, also numbers of Edinburgh physicians doing the same; and why select a gentleman with a foreign degree, when that degree was obtained on a most strict and rigid examination,-quite as much so as the examitions here,- why differ one with another of the same profession, when by only stopping the prescribing by druggists, you would at once give an increased and good practice to all ?

\section{April, 1849.} I am, Sir, your obedient servant, General Practrtioner.

\section{MEDICAL REFORM. \\ To the Editor of The Lancet.}

4, Hanover-square, April 11, 1849

Srr,-T am directed to forward to you the enclosed copy of a petition to Parliament from the Conncil of the National Institute, and to request the favour of its insertion in your journal.-I am, Sir, your most obedient servant,

Georan Ross, Sec.

The following Petition from the Council of the National Institute of Medicine, Surgery, and Midwifery, has been forwarded to J AMES WYLD, Esq., M.P., for presentation to the House of Commons.

To the Honourable the Commons of the United Kingdom of Great Britain and Ireland, in Parliament assembled.

The Petition of the undersigned Members of the Council of the National Institute of Medicine, Surgery, and Midwifery, humbly showeth-

That evils have afflicted the Medical Profession in the United Kingdom, and have occasioned an agitation for Medical Reform of many years' duration, which are not only unabated, but are daily increasing; and that the profession is suffering at the present time, more than at any former period, from the imperfect, inconsistent, indefinite, and anomalous state of the laws by which it is governed.

That a reform in the laws has been advocated by the National Association of General Practitioners, and also by the National Institute, and the principles and more important details of such reform are in perfect accordance with the Principles and plan of certain measures of Medical Reform proposed and agreed to by the Representatives of Physicians, Surgeons, Apothecaries, and General Practitioners, in the Conference recently held in London, at the Royal College of Physicians, and to which the Medical Institutions of England, Ireland, and Scotland, have given a general assent; and that the proposed measures are eminently calculated to ameliorate all the more pressing grievances of which the profession so loudly and so justly complains.

That the principles above alluded to have been fully de tailed in the "Outline of a Bill" for regulating the Profession of Physic and Surgery, drawn by the Conference, and which "Outline" is contained in the evidence taken, during the last Session of Parliament, before the Special Committee of your Honourable House, on "Medical Registration and Medical Law Amendment."

That the general agreement of so many influential bodies, not only in the principles, but in most of the more important details of a Bill for Medical Reform, and the pledges given by the Government to those bodies, have obviated difficulties in medical legislation otherwise insuperable, and afford, at the present moment, a fairer prospect than at any former period, of carrying such a Bill through the Legislature.

That in the existing state of the profession, no measure, however great its merits, can possibly meet with the full con- currence of every section or denomination of its members, and any plan that can be devised may be expected to meet with some opposition. That it is most inexpedient, however, on that account, to delay a measure calculated to benefit the great mass of the profession, and to effect a great public good.

That your Petitioners therefore respectfully, but earnestly, represent to your Honourable House the urgent necessity that exists for immediate legislation on the affairs of the Medical Profession, and they pray that a Bill for regulating the Profession of Physic and Surgery may, on public as well as on professional considerations, be enacted by the legislature with as little delay as possible.

And your Petitioners will ever pray, \&c.

Peter Hood, 15, Lower Seymour-street, Portman-square; James Stedman, Guildford; George Stilwell, Epsom; George J. Squibb, Orchard-street, Portman-square; Henry P. Fuller, 112, Piccadilly; John Propert, 6, New Cavendish-street, Portland-place; James Clayton, Percy-street, Bedford-square; James Bird, 16, Orchard-street, Portman-square; Edward Headland, 32, Guildford-street, Russell-square; Robert Tanner, 56, Manchester-street, Manchester square; Richard Wallace, 9, John's-terrace, Hackney-road; Thomas Martin, Reigate; Emanuel Baker, Bulstrode-street, Manchester-square; John Bowling, Hammersmith; Hamilton J. Jennings, West Drayton; John Nussey, 4, Cleveland-row, St. James's; John Sutton, Greenwich; Septimus Read, 41, Jewin-street, City; William Anson Cartwright, Teignmonth; George Webster, M.D., Dulwich; William B. Vickers, 32, Bakerstreet, Portman-square; Thomas Parker, Woburn; Robert Dunn, Norfolk-street, Strand; John Liddle, Alie-place, Goodman's-fields; Farnham Flower, Chilcompton; Richard Southee, Cambridge; William H. Garrington, Portsea; George Gibson, Ulverstone; Thomas Herbert Barker, Bedford; George Webster, Connaught-terrace; Nathaniel Clifton, Cross-street, Islington ; Edward Doubleday, Blackfriars-road ; Charles M. Thompson, Westerham; James S. Daniel, Ramsgate; Charles M. Burnett, Alton; John Prankerd, Langport; William Chaldecott, Dorking; George Drummond, Brighton; Henry Ancell, Norfolk-crescent, Hyde Park; John Spence, Manchester; William Collyns, Kenton, Exeter; John R. Keele, Southampton; Horatio G. Day, Isleworth; George Robins, Covent-garden; Thomas Paget, Leicester; Thomas Porter, 145, Bishopsgate-street; William E. Snow, 26, Tredegar-square; Thomas Nicolson, 50, Tredegar-square; Isaac Hurst, Bedford; Edward Westall, Croydon; Edward Tegart, Dover-street, Piccadilly; John B. Eyles, St. Andrew's-court, Holborn-hill.

\section{ON THE EFFECTS OF MILITARY FLOGGING.} To the Editor of THE LuNCET.

SrR,-The following extract from a work by Dr. Boggie, an old and experienced military surgeon, and which has been reviewed in the recent number of the Midico-Chirurgical Review, may assist in clearing away some of the doubts of those medical gentlemen who appear to be so fascinated by the flagellative system, and who would still support an inhuman and degrading punishment, but for the verdict of a special jury, in the recent trial relative to the Hounslow inquest.

In the Military Hospital of the Cordileria, during the Peninsular campaigns, and which contained nearly 1000 patients, in speaking of phagedæna gangrenosa, the doctor observes:-

"It would appear that in the milder cases of this disease the skin and cellular membrane are the parts originally and principally concerned, and that it may sometimes be confined to these textures; but that, in more violent cases, one structure is destroyed after anrther; so that the muscles, ligaments, and tendons, togther with the bloodvessels and nerves, are involved in the disease, become disorganized, and slough off; even the periosteum is not exempt from its influence; and the bones, being deprived of their coverings, sometimes become affected with caries."-pp. 42,48 .

This is pretty strong, but stronger still, and to his immortal honour, are the words of the talented and astute reviewer. Now, MIr. Horatio Grosvenor Day, ponder upon these words, and then " read, mark, learn, and inwardly digest them," and remember, they do not emanate from one "who knows more of a bullet swallowed than of a pulpy muscle." 
Thus writes the reviewer of Dr. Boggie's able work, and which he lauds highly:-

"Dr. Boggie states that he has seen some frightful cases of this gangrene after military punishments. Surely this fact alone should be sufficient to cause the abolition of this remnant of barbarism among us. Medical men should make a decided stand on this question, and show how much greater punishment is often inflicted than the sentence awards, and how impossible it is to foretell the after-consequences of the injuries caused by the lash, even in what is termed moderation."

The words in italics are not so in the book or the review, but I wished to mark them as strongly as possible, for the edification of those who have over and over again stated that no mischief, or death, has taken place from military flogging. "Credat Judæus."

I shall now take leave of this subject; and whether another pamphlet be published or not, it will have no notice from me. Of one thing, however, I am sure-that the proceeds of the first one will not yield a Pactolian shower, though brass enough has been exhibited in its miserable composition.

April 7, 1849. Yours faithfully, THOMAs LitohHIELD.

\section{MR. GAY AND THE MEDICO-CHIRURGICAL REVIEW. \\ To the Editor of THE Laircet.}

Srk,-The editor of the Medico-Clirurgical Review (whom I presume to be Dr. Carpenter) has not thought proper to meet the charge which I have publicly made against him of having stated a falsehood, in an attempt to justify the publication of an unfair and calumnious attack upon my character in the pages of that journal. Allow me, through the pages of your journal, once more to ask " the editor," can he deny the charge? And, if not, can he appear again before his audience at Sussex Hall, or elsewhere, without the stigma of having violated the principles of charity and truth?

I am, Sir, your obedient servant,

Finsbury-place South, April, 1849 . JoHN GAY.

\section{ON THE EFFECTS OF WINDS \&c. IN THE PRODUCTION OF DISEASE.} STATISTICS OF PARALTSIS.

To the Editor of 'The LANCET.

Sik,-The following observations may, perhans, be interesting to some of your readers. Allow me to premise, that I live in a small remote village, and, as is usual in such localities, each individual is known to the rest, so that when any malady has overtaken an individual, the precise nature of the malady is duly inquired into by the neighbours, and reported through the neighbourhood. I had thus better opportunities of in. quiring into the under-mentioned facts, than I should have had if living in a large town.

Having a near relative who was struck by a paralytic attack in January, 1843, I was forcibly impressed by the circumstance, and I noticed that the wind at the time of attack was from the North. I determined to observe the state of the atmosphere at the time that subsequent paralytic attacks might occur. The following has been the result of my observations:- Since my relative was attacked in 1843 , seventeen individuals have become affected by paralysis, of whom eleven died. Three of them had more than one attack; the rest had but one attack each. In every instance of these seventeen individuals, when attacked by paralysis in this place, the wind, at the time of attack, was either from the northerly or southerly points. I am not aware of a single instance of para. lytic attack occurring whilst the wind was either from the west or the east. In one instance, indeed, where the individual had two attacks, on the day that one of the attacks occurred, the wind veered so frequently, that I cannot say from what quarter it blew at the time of that attack.

During the above investigation, I was struck with the fact, that those individuals who received paralytic attacks whilst in bed, had their beds so placed that they lay in northerly and southerly directions. Following up the investigation on this head, the following has been the result:- Nine individuals have been attacked by paralytic shocks, whilst in bed, during the last fifteen years, in this place. In these nine instances the individuals lay in bed north and south. I cannot find a single instance of an individual being struck by paralysis whilst lying in easterly and westerly directions. "Here it is worthy of particular notice, that from the construction of the houses, and the direction of the streets in this locality, the beds are so placed, that the majority of the people lie in easterly and westerly directions.

With regard to position that individuals were in who re ceived paralytic attack, whilst out of bed, my relative above referred to received the first attack whilst dressing, in the morning, he being at the instant of attack in a stooping position, in a southerly direction. He received the second attack, which terminated fatally, ten months afterwards, whilst going to bed, being at the instant of attack in a stooping position, and also in a southern direction, the wind, in both instances, from the north. In the only other instance of which I was an eye-witness, the individual received the paralytic attack whilst in a stooping position, in a southerly direction, the wind being likewise from the north. Regarding the other individuals, I cannot speak as to the position they were in when they became the subjects of the attack.

It would be presumptous, and might be offensive in me, who do not practise the healing art, to give opinions upon the above facts; besides, the above may be only coincidences in a particular locality. Therefore, I leave the subject wholly in the hands of the medical profession, trusting they will investigate whether or not it is an universal fact, that paralytic attacks only occur whilst the wind is in the magnetic meridian, \&c.; should such be found to be an universal fact, I doubt not that they will bring that knowledge to enforce upon invalids at such times the necessity for still greater preventive caution.

Comrie, Scotland, April 9, 1849 I am, Sir, yours obediently,

* * In a note which accompanied the above article Drummond has remarked, in addition, "After long study, I am persuaded that the earth's magnetism exercises far more influence upon the animal, the vegetable, and the physical worlds than has hitherto been imagined."

\section{CHELTENHAM UNION AND ITS MEDICAL OFFICERS. \\ (FROM A CORRESPONDENT.)}

ON Thursday, March 7 th, the board of guardians met to elect four medical officers for the year to this union. In district No. 1, Mr. Hyett, the medical officer who had served the union for near tes consecutive years, was opposed by a young man lately come to reside in Cheltenham, of the name of George Francis Hewson. The guardians had taken some umbrage with Mr. Hyett, as they state, from the circumstance of his ordering more beer and wine than they deemed needful for the paupers; but well informed parties here attribute it to the circumstance of certain political partizans having been this year elected guardians, and who are much opposed to $\mathrm{Mr}$. Hyett in politics. These guardians canvassed many members of the profession in Cheltenham to oppose the old officers, but to their honour be it stated, they could only induce one medical man to come forward, who, I suppose, contemplated easily holding the office on the above-named day, the said $G$. F. Hewson, a M.R.C.S. London, and M.D. of Glasgow, was elected medical officer to district No. 1, but upon a memorial being presented to the Poor-law Board, on the following week, they declined sanctioning the appointment, as he was not qualified in one of the modes recited in their articles. The guardians had now to advertise for fresh candidates to offer themselves on the following week, and a Mr. Thomas James Cottle allowed himself to be nominated, and was elected; twelve guardians voting for Mr. Hyett, and sixteen for Mr. Cottle. If members of the profession will thus Iend themselves to boards of guardians, it is quite useless for union officers to endeavour to hold their offices independently, or to expect any increased rate of remuneration. The guardians here are, since this election, contemplating reducing the salaries of their officers, and one guardian gave notice on the last board day, he should move for a reduction of 10 per cent. being taken from salaries above $50 \mathrm{l}$, and 5 per cent. under $50 \mathrm{l}$ And this arises from the members of the profession thus disgracefully opposing one another.

\section{PROPOSALS ON MEDICAL REFORM.} To the Editor of THe Lancet.

Srn,--Since the insertion of my last letter, I find that I have been called a radical by a member of the Apothecaries' Company, and some other advocates of the new college. I am not very particular about names, but do not wish my opinions to be misunderstood. I always thought a radical was one who wished to uproot existing institutions, and to pull down to his 